\title{
Termination of Safeguards for Accountable Nuclear Materials at the Idaho National Laboratory
}

April 2012

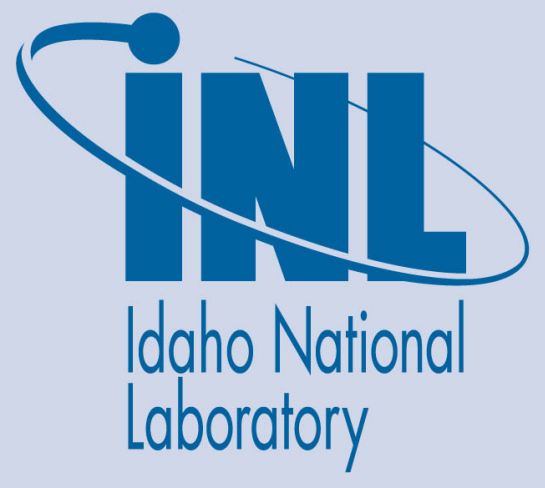

The INL is a U.S. Department of Energy National Laboratory operated by Battelle Energy Alliance 
INL/EXT-12-24850

\title{
Termination of Safeguards for Accountable Nuclear Materials at the Idaho National Laboratory
}

April 2012

\author{
Idaho National Laboratory \\ Idaho Falls, Idaho 83415
}

http://www.inl.gov

Prepared for the

U.S. Department of Energy

Office of Nuclear Energy

Under DOE Idaho Operations Office

Contract DE-AC07-05ID14517 


\section{DISCLAIMER}

This information was prepared as an account of work sponsored by an agency of the U.S. Government. Neither the U.S. Government nor any agency thereof, nor any of their employees, makes any warranty, expressed or implied, or assumes any legal liability or responsibility for the accuracy, completeness, or usefulness, of any information, apparalus, product, or process disclosed, or represents that its use would not infringe privately owned rights. References herein to any specific commercial product, process, or service by trade name, trade mark, manufacturer, or otherwise, does not necessarily constitute or imply its endorsement, recommendation, or favoring by the U.S. Government or any agency thereof. The views and opinions of authors expressed herein do not necessarily state or reflect those of the U.S. Government or any agency thereof. 



\section{Termination of Safeguards for Accountable Nuclear Materials at the Idaho National Laboratory}

INL/EXT-12-24850

Revision 0

April 2012

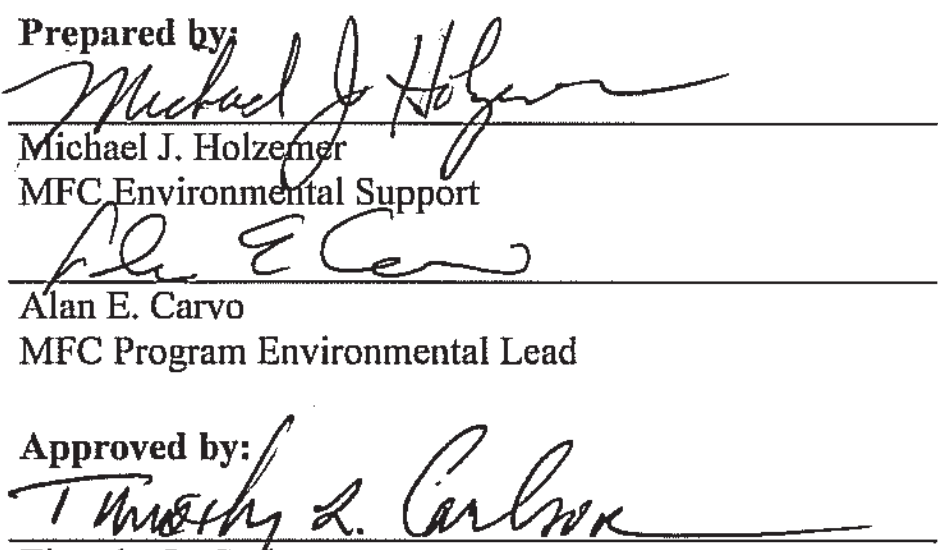

Timothy L. Cauflson

Projeft \& Programs Support, Manager

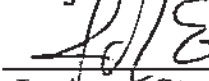

Jo Anná Stenzel

Envirommetal Syepport and Services, Director

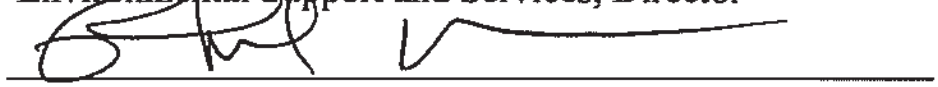

Phillip. J. Breidenbach

MFC Nuclear Operations, Director

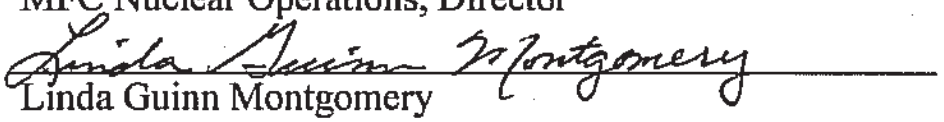
BEA General Counsel
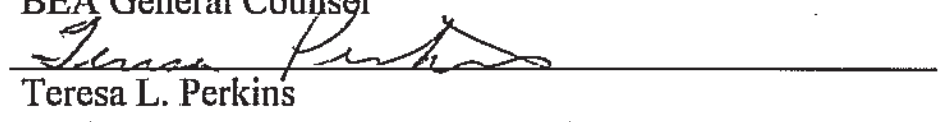

Environment and Sustainability, Division Director
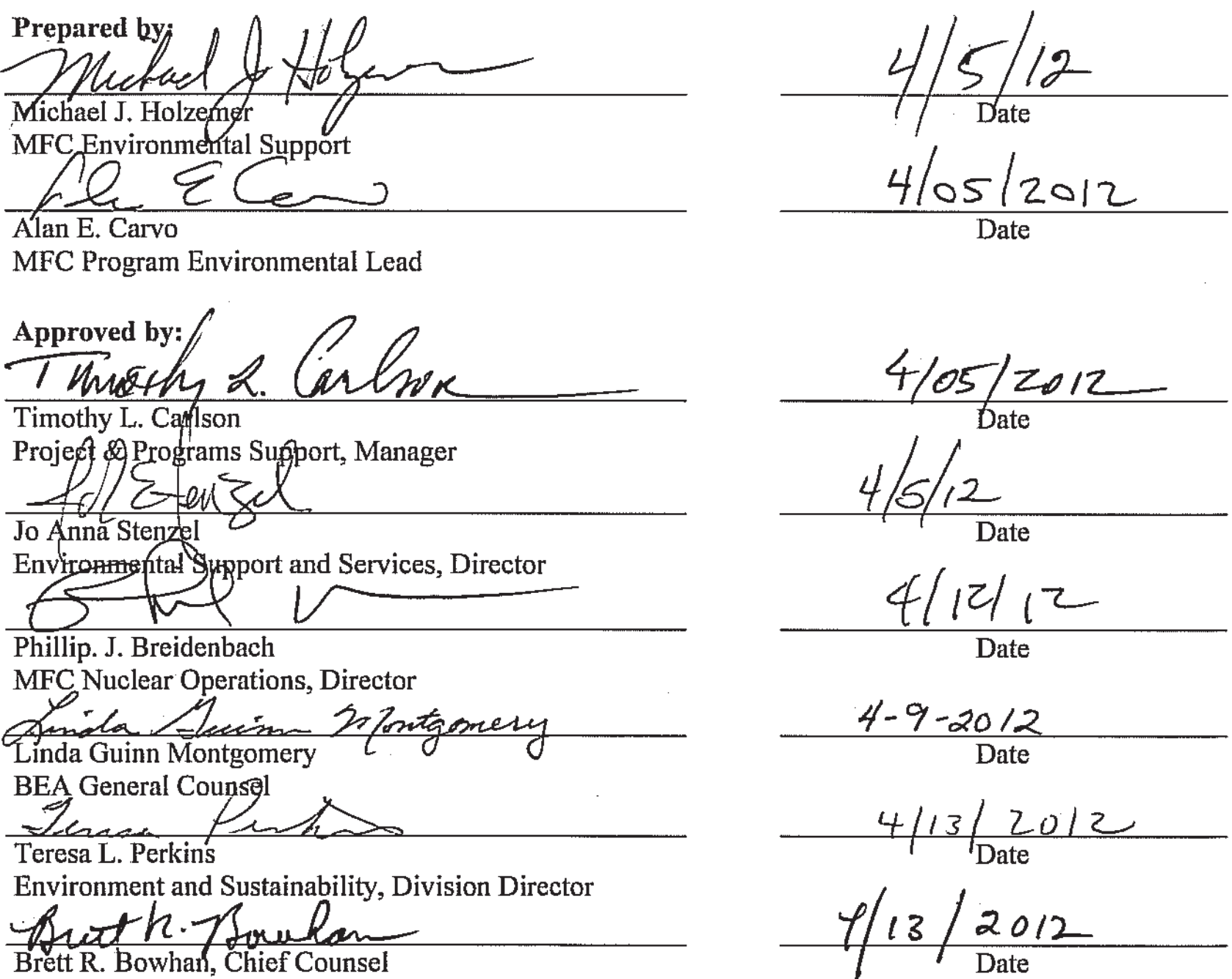
Date

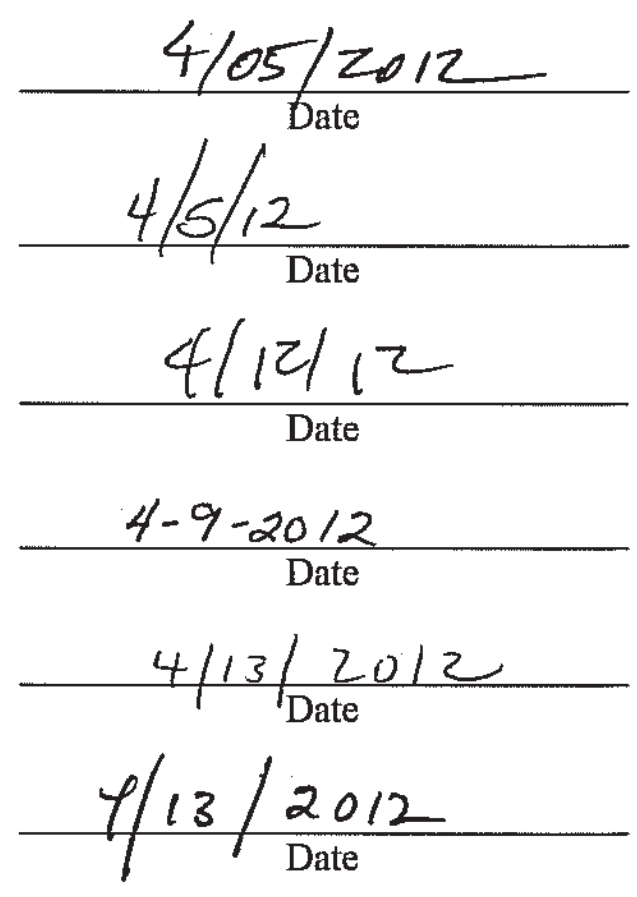





\section{CONTENTS}

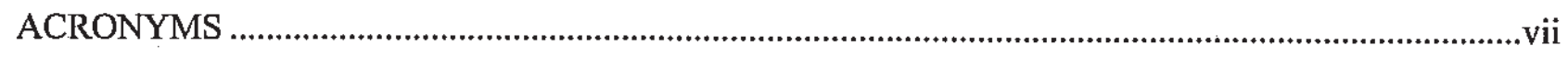

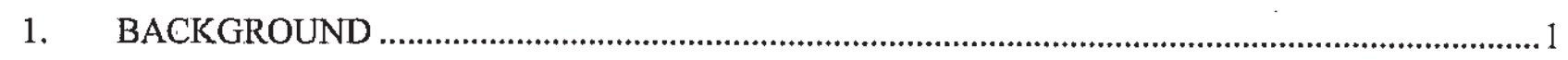

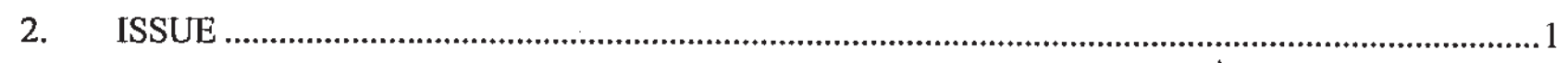

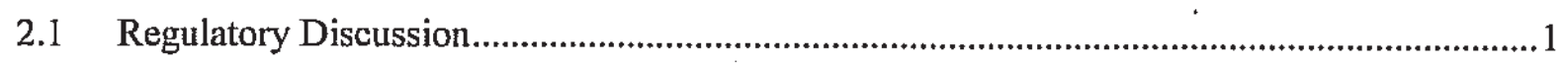

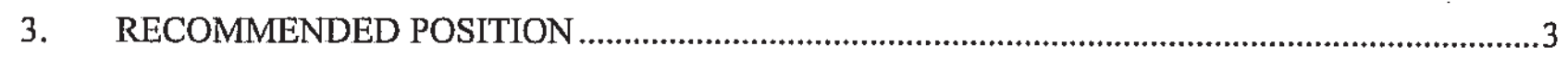




\section{ACRONYMS}

BEA Battelle Energy Alliance, LLC

DOE Department of Energy

DOE-ID DOE-Idaho Operations Office

FCF Fuel Conditioning Facility

HFEF Hot Fuel Examination Facility

INL Idaho National Laboratory

MBA Material Balance Area

MC\&A Material Control and Accountability

MFC Materials and Fuels Complex

NM nuclear material

NMMSS Nuclear Material Management and Safeguards System

RCRA Resource Conservation and Recovery Act

RSWF Radioactive Scrap and Waste Facility

S\&S Safeguards and Security

SS Shift Supervisor

SNM special nuclear material

WGS Waste Generator Services 


\section{Termination of Safeguards for Accountable Nuclear Materials at the Idaho National Laboratory}

\section{BACKGROUND}

Termination of safeguards ends requirements of Nuclear Material Control and Accountability (MC\&A) and thereby removes the safeguards basis for applying physical protection requirements and other controls for theft and diversion of nuclear material (NM), providing termination requirements are met as described below. stipulates:

Department of Energy (DOE) M 470.4-6 Chg 1(Nuclear Material Control and Accountability [8/14/06])

1. Section A, Chapter I (1) ( q) (1): Safeguards can be terminated on NMs provided the following conditions are met:

(a) "If the material is special nuclear material (SNM) or protected as SNM", it must be attractiveness level" E and have a measured value."

(b) "The material has been determined by DOE line management to be of no programmatic value to DOE."

(c) "The material is transferred to the control of a waste management organization where the material is accounted for and protected in accordance with waste management regulations. The material must not be collocated with other accountable nuclear materials."

Requirements for safeguards termination depend on the safeguards attractiveness levels of the material. For attractiveness level E, approval has been granted from the DOE-Idaho Operations Office (DOE-ID) to Battelle Energy Alliance, LLC (BEA) Safeguards and Security (S\&S). In some cases, it may be necessary to dispose of NMs of attractiveness level D or higher. Termination of safeguards for such materials must be approved by the Departmental Element (for BEA this is the DOE Headquarters Office of Nuclear Energy) after consultation with the Office of Security.

\section{ISSUE}

Idaho National Laboratory (INL) Safeguards handoff to waste management is not clearly delineated.

\subsection{Regulatory Discussion}

Accountable NM (see definition below) is required by DOE-ID to be under the control of BEA S\&S until the NM is released from safeguards requirements and subsequently turned over to a waste management organization as waste.

\section{- Accountable Nuclear Material}

- Nuclear material designated by the Secretary of Energy and defined in DOE Order 470.4-6 that requires accountability and/or reporting to the Nuclear Material Management and Safeguards System (NMMSS). By DOE order, these designated materials are: depleted uranium, enriched uranium, americium-241 and -243 , curium, berkelium, californium-252, plutonium-238 through -242, lithium-6, uranium-233, normal uranium, neptunium-237, deuterium, tritium, and thorium.

Control of accountable NM at the INL is accomplished by S\&S personnel and Material Balance Area (MBA) custodians using a graded approach whereby the most stringent level of control and accountability is applied to different types, quantities (reportable and non-reportable ${ }^{\mathfrak{c}}$ ), physical forms, and isotopic compositions of NM based on the risk and impact of loss, destruction, or misuse.

\footnotetext{
Protected as SNM: refers to separated actinides such as Np-237, Am-241, or Am-243.

Attractiveness level: Provides categorization of nuclear material types and compositions that reflects the relative ease of processing and handling required to convert that material to a nuclear explosive device.

'Non-reportable quantities: Those quantities less than 0.5 of a reporting unit. A reporting unit is the mass unit that facility/site nuclear materials accounting systems must use for recording and reporting inventories and transactions. Reporting units are identified in Table I-1, "Nuclear Materials" in DOE M 470.4-6.
} 
NM disposition tasks include performing an evaluation of material usability, recoverability and value of material, and determining an appropriate disposition path.

Releasing material from accountability requirements requires several tasks to be completed simultaneously. These tasks are (1) characterization (qualification) of material, (2) Material Balance Area (MBA) custodian/Safeguards representative documentation for termination of safeguards requirements, and (3) transfer of material to a waste management organization. During the timeframe to complete all the above tasks, the material remains under the safeguards process. Accountable NM cannot be collocated with waste material while under safeguards control.

Termination of safeguards requires material to be packaged in its final container for turnover to a waste management organization. The final container package is the NM that will be turned over to a Waste Management Organization. The NM will be packaged in its final form so the material meets attractiveness level requirements for the NM to be classified a waste material. This final container package is key to beginning the process of terminating safeguards requirements for the following reasons:

- Material's final form must be known for the MBA custodians and Safeguards personnel to evaluate the attractiveness level.

- To account for roll-up the contents of the final package must be evaluated for accumulation of smaller quantities of NM that collectively reach a reportable quantity. Roll-up is based on the package assembled for transfer to a waste management organization rather than per discrete items.

Accountable NMs are not considered waste by DOE until they have undergone an evaluation for usability, recoverability, and value of material; documentation per MCP-2755, Section 4.3, "Documenting Nuclear Material Disposition," for disposition by S\&S of reportable quantities has been completed, and custody of the material has been transferred to a waste management organization.

Accountability is accomplished by performing measurements, maintaining records of NM inventories, observing and authorizing NM transfers, and documenting inventory adjustments.

Inventories of reportable quantities of NMs are accounted for by Safeguards personnel utilizing the Safeguards Local Area Nuclear Materials Accounting System and MBA accounting systems maintained by the MBA custodians. Accountability of non-reportable quantities is performed at the MBA custodian level per MCP-2752, Section 4.11, "Minimum NMMSS Reporting Levels." Discrete items containing non-reportable quantities when packaged together in a final container package may, due to roll-up, have to be re-established as reportable quantities requiring more stringent MC\&A requirements. MBA custodians and Safeguards personnel evaluate roll-up as part of the documentation required for termination.

Since safeguarded NMs are not solid waste (i.e., not discarded material), per 40 CFR 261.2, while being controlled under the safeguards process, treatment, storage, and management processes within BEA facilities are not RCRA-regulated activities. Transfer out of the safeguards process to a waste management organization is the point at which the material becomes subject to waste characterization under 40 CFR 262.11. At the Materials and Fuels Complex (MFC) this occurs when the following safeguards and waste management organization documentation is completed:

- For Hot Fuel Examination Facility (HFEF) or Fuel Conditioning Facility (FCF) transfers to the Radioactive Scrap and Waste Facility (RSWF):

- When waste management organization and Safeguards has completed their processes and signed the following documentation:

- Safeguards document Form 472.20 (if material meets definition of reportable quantity), and - RSWF document FRM-798 has been signed by Shift Supervisor (SS) identifying the storage date.

\footnotetext{
${ }^{d}$ Roll-Up. Nuclear material transactions should be documented and reported as accurately as possible to reflect the actual quantity of material transferred. If a transaction of discrete items, each of which is less than a reportable quantity, sum to a reportable quantity, the transaction should be recorded to most accurately reflect the actual quantity involved." ( Nuclear Materials Management and Safeguards System User's Guide, Section 2.3.3 release 1, October 2008)
} 
- For Facility transfers to Waste Generator Services (WGS) or to an onsite RCRA Treatment/Storage Facility:

- When waste management organization and Safeguards has completed their processes and signed the following documentation:

- Safeguards document Form 472.20 (if material meets definition of reportable quantity), and

- Facility MBA custodian has signed the WGS document WM-135 transferring custody.

Upon transfer to a waste management organization, after completion of documentation by Safeguards personnel that the accountable NMs controls are terminated, the resulting final container package is considered to be waste and possibly a hazardous waste.

\section{RECOMMENDED POSITION}

Based on the accountability process DOE has established, accountable NM does not become waste until such. time as the final package has been prepared, Safeguards has completed its review of the attractiveness level and value and determined the material can be terminated, and custody of the material has been transferred to a waste management organization. 